\title{
Peplau's Theory of Psychodynamic Nursing and the Nurse-Patient Interaction: A Literature Review
}

\author{
Article by Obayori Christianah Olufunke and Omolola Oluwakorede A \\ Nursing, Texila American University, Nigeria \\ Email: obayorico@gmail.com
}

\begin{abstract}
The aims of this paper was to review a theoretical model useful for developing nursing knowledge in relation to nurse-patient interactions, Nurses are favorably viewed by the society, most often as virtuous, benevolent, angelic and admirable. Nurses have been stereotyped positively as 'ministering angels'. This positive view of the profession is frequently experienced first-hand in the clinical practice.

The interaction between a nurse and the patient is in about four phases as defined by Peplau this includes- Orientation, Identification, Exploitation and Resolution, although these phases are defined separately, there is a considerable level of overlap between them. Issues such as power, the socio-cultural context, and interpersonal competence are shown to be important in the quality of nurse- patient interactions and nurses need to take cognizance of these factors in their interactions with patients.

Method: A review of the literature on nurse-patient interaction was carried out to and areas for further studies identified.

The literature was reviewed from the following perspectives, (1) nurse communication within the nurse-patient interaction, (2) nurse- patient interaction, (3) patient perception of the nurse-patient interaction, and (4) patient care-seeking communication.

Theoretical model: Peplau's theory of Psychodynamic nursing.

Results: Nurse-patient interaction is a central element of clinical nursing practice. This paper shows how Peplau's model can be used as a theoretical framework for understanding nurse-patient communication.

Relevance to clinical practice: Issues such as power, the socio-cultural context, and interpersonal competence are important in the quality of nurse-patient interactions and nurses need to take cognizance of these factors in their interactions with patients.
\end{abstract}

Keywords: nurse-patient communication, nurse-patient interaction, nurse-patient relationship

\section{Introduction}

Nurses are favorably viewed by the society, often as virtuous, benevolent, angelic and admirable. Nurses have been stereotyped positively as 'ministering angels' (Muff, 1982). This positive view of the profession is frequently experienced first -hand in the clinical practice Shattell M. (2004).

A study of the hospital environment that is phenomenological found that nurses were prominent in patient's descriptions of the hospital (Shattell, 2002). Participants in the study were asked what they were aware of in the hospital environment. In addition to positive statements about 'nice nurses', strong negative statements about nurses and nursing care were also present in their descriptions of the hospital environment.

One participant said this of her experience during hospitalization: It's terrible [the radium implant]. So finally I thought okay, endure this, we'll get through it. And heck with it and I'll get through the next one and of course I didn't want to come back here. I mean this time when I had surgery, I mean I knew I had to come back up here and I thought, I hate them, and they hate me (Shattell M. 2004). This patient view illustrated in Shattell M's study clearly shows a paradox as the patient's overall 
South American Journal of Nursing

Special Edition 2016

experiences of nursing care seem inconsistent with the representation of the 'nice' nurse. While nurses may be seen as 'nice', patient participants in Shattell's (2002) study of the hospital environment longed for better connections and therapeutic relationship with nurses.

In the hospital environment, patients depend on the nursing staff with a perception of powerlessness which creates a situation in which the patient sees the need to solicit needed nursing care by any means possible. Added to these factors, nurses are seen as overwhelmed and overworked culminating in greater patient needs and thus the patients activates multiple strategies to get these needs met of which Nurse - patient interaction was a central tactic (Victor, 2000).

This paper aims to review a theoretical basis for nursing knowledge development regarding nurse-patient interaction by carrying out a literature review and identifying areas for further study.

Peplau's theory of psychodynamic nursing will be reviewed afterwards; a literature review will be carried out on the following sub-headings: Interpersonal communication within the nurse-patient relationship, nurse-patient interaction, the perception of the patient on nurse-patient interaction, and care-seeking communication of the patients. Following the literature review will be a discussion including implications for practice and future research.

\section{Peplau's theory of psychodynamic nursing}

According to Victor et al., (2000) The psychodynamic theory suggests that interpersonal, infant and childhood attachments and dilemmas provides a base for personality for accurate prediction of coping strategies in the future.

The therapeutic relationship and interactions between and nurse and patients can be conceptualized from the perspective of interactionism that is symbolic. This interaction-ism is a socio-psychological approach to studying human actions (Schwandt, 1998).

This relationship differs from other forms of relationship in that the nurse utilizes maximally her communication skills, knowledge of human behavioral patterns and personal strength to enhance the growth of the client. The ideas, feelings and experiences of the client are the focus of this relationship (Forchuk C., 2000). The core of this theory is that the relationship between the nurse and the patient is the focus of their interaction rather than the patient himself (Forchuk 1993). The goals of this interaction are to engender patient's recovery and to help patient understand his health challenge and learn from them as he develops new patterns of behavior, the nurse also gets a clear understanding of how universal stressors and ailments affect the lives and behaviors of the individual client (Pearson et al., 2005).

The sense of self of an individual emerges with social interaction, it is developed when people imagine themselves in various social roles, anticipate their responses, acts according to the meanings they have deciphered (Powers \& Knapp, 1995).

According to Merriam-Webster online dictionary, psychodynamics was defined as the psychological study of the mental and /or emotional processes that is developed during early childhood and how they affect mental states and behaviors.

It involves the use of the nurses' understanding of individual behavior and knowledge to help patients identify difficulties and how to apply interpersonal relationship to problems arising at various levels of personal experiences (Carey, Rasmussen, Noll, Stark and Searcy, 1989).

The process of interpersonal relations as defined by Peplau consisted of four phases in the nurse-patient interaction, this includes Orientation, Identification, Exploitation and Resolution, although these phases are defined separately, there is a considerable level of overlap between them. 
Orientation Phase: this is the point of initial contact between the patient and the nurse, they get to know each other as people, roles and expectations are clarified. Patient at this point identifies and recognizes his need for help, plan is made to utilize professional services on offer and maximize the energy derivable from needs identified. Patient at this point attempts to establish the nurses' integrity.

The main tasks that is carried out during this phase include building rapport and trust, establishing a therapeutic environment, patients strength and weakness is assessed and acceptable mode of communication between the nurse and patient is established.

Identification Phase: during this phase, trust is engendered with selective response from patients to persons who make offers of help, identifying with the nurse and problems which can be managed, feelings and behavior is explored for meanings. Peplau states that when a patient is allowed by the nurse to express feelings, and still get the needed nursing care, illness experience is undergone such that it reorients feelings and strengthens positive forces in the personality. Tasks emphasized during this phase are to clarify patient's preconceptions and expectations of nurses and nursing, develop acceptance, explore feelings, identify problems and response to care givers. The nurse aids the expression of feelings, needs, and assists when stressed, is receptive and provides necessary information. Plans are made for the future during this phase.

Exploitation Phase: The patient exploits realistically services available to them based on needs and interest. The nurse helps the patient to strike a balance between the needs for independence and dependence. Plans made in the previous phase are implemented and evaluation is done. Continuous assessment with provision of needed assistance by the nurse as new needs emerge.

\section{Resolution phase}

This phase involves the gradual development of independence from care givers which eventually leads to the termination of the relationship mutually. The patient aspires to new set goals while maintaining changes in communication style and mode of interaction with plan for alternative sources of help, prevention of the problem from reoccurrence and integration of the illness experience.

Across these phases, Peplau identified some roles for the nurse.

1. Stranger Role: is recipient of the client in a similar way to meeting a stranger in other situations; engenders a trusting climate and objectively accepting the patient.

2. Resource Person Role: attends to questions and enquiries, explains clinical data and treatment plan.

3. Teaching Role: Gives clear instructions and provides training which involves the analysis of the learner's experience and its synthesis. Offers timely information and helps the patient learn (www.slsu-coam.blogspot.com).

4. Peplau categorized teaching into two: Instructional-which consists of information transference. Experiential - which is capitalizing on the learner's experience as a basis from which learning products are developed.

5. Counseling Role: Helps the client to understand, integrate and maximize the current life circumstances; guide and encourage necessary changes.

6. Surrogate Role: Helps client sort out domains of dependence, interdependence, and independence and acts as client's advocate. Figuratively representing a person in the client's life.

7. Active Leadership Role: Helps client assume utmost responsibility for meeting set goals in the plan of care in a way that is satisfying mutually. Working in a democratic way with the patient (www.slsu-coam.blogspot.com). 
South American Journal of Nursing

Special Edition 2016

\section{Limitations of the theory}

- Personal space considerations and community social service resources are considered less.

- Health promotion and maintenance were less emphasized

- Cannot be used in a patient who doesn't have a felt need eg. With drawn patients, unconscious patients

- Some areas are not specific enough to generate hypothesis (www.currentnursing.com)

Peplau's theory emphasized reciprocity in the nurse-patient relationship and envisioning nursing as a collaborative and interactive process.

The core around which this theory revolves is "self- awareness" which aids the nurses' understanding of which emotions, needs and responses are their own and which are the needs of others thereby identifying the signs of exhaustion emotionally, burnout, involvement with patients excessively and thus identify ways to ventilate and refresh themselves. Self awareness engenders a balance between the personal and professional selves of the nurse thereby enhancing professional role congruence.

Peplau (1999) stated that the nurse is an individual that is complex, the totality of past experiences, training that is rigorous and personality traits that is unique. As nurses apply the human relationship principles, maturity is attained in the promotion of therapeutic relationship as the nurse gets to understand his/her own behaviors and needs (Peterson and Bredow, 2004). Nurses therefore must identify and encourage cues indicative of the patients' readiness for growth at the same time, mobilize identified community resources to assist the patient in coping with psychosocial needs accompanying the change in their health status (Peterson and Bredow, 2004).

\section{Review of literature}

To access literature for the review, databases used include but not limited to: CINAHL, Medline, and Psych-Info. Search references used were nurse-patient interaction, nurse- patient relationship, patient communication and nurse-patient communication. Literature in relation to the nature of nurse- patient communication was included. References listed in various articles were also used to inform this discussion. Theoretical and discussion articles were included if they were germane to the topic and all studies relevant were included.

\section{Nurse communication within nurse-patient interaction}

Majority of the studies on nurse-patient interactions focused on the communication from the nurses' angle in the interaction with an assumption that the nurse assumed the position of power in the relationship. Sociological theories on professions award power to the professional as a result of their knowledge that has been acquired via academics and expertise (Haug \& Lavin, 1981,). This professional power is adequately documented in Parson's work on the sick role in which patient is said to willingly submit to professionals because of the specialized knowledge that they have and the professional is ever willing to accept this power tilt (Parson 1975). In a study of doctor-patient relationship, Roth(1972) found that patients were more likely to be active in their care and utilized bargaining and negotiation to enhance their interpersonal power but do not attain equality. Other studies in this regard examined power tilt in relation to decision making by the patient (Taylor et al., 1989), needs of mental health patients (Jackson and Stevenson 2000), patient autonomy (Martins, 1998) and Webb (1995) who studied the dimensions of power in the nurse-client interactions.

Johnson and Webb (1995) in their study of the nurse -patient experiences of social processes of care reported that nurses' exerted power over their clients in a 
relationship filled with much struggle and conflict which results in tacit concurrence to the goal of care.

Patients are aware of the existence of a nursing agenda which they are expected to adhere to failure to which is consequential. This is evident in the words of an old patient that was hospitalized, 'I have to do as I'm told. I'm 94 next week and I still have to do as I'm told' (Hewiston, 1995). When patients fail to adhere to the "nursing agenda" negative social labeling as non-compliant, difficult or bad occurs. This social labeling affects the quality of care on the long run hence the need for the nurse to understand the diversity in sick role behavior of individuals as being influenced by various factors especially their culture. According to face work theory, patients wanted to be viewed positively therefore they were rather compliant to the nursing agenda but in the psychodynamic theory, patients attempted to negotiate their compliance ; through their self-evaluation and their perceived evaluation by the other, they were able to maintain their presentation of the 'good' or 'easy' patient (Jackson and Stevenson 2000).

A variety in communication pattern in relation to work experience among nurses was reported by Harrison et al., (1989). Nurses in training with nursing related working experience were sensitive to the feeling of others compared to those who did not have a similar working experience also, these group of students were less likely to be judgmental or deceptive but used threat t to engender cooperation, frequently disagreed with the client and interrupted conversations more than those in the group without prior working experience. Harrison et al. (1989) also found that the group that had no prior experience listened better and were less critical. It appears that as these students become more experienced and educated, communication behaviors diminishes. Harrison et al. therefore postulated that nursing students having learned communication skills that are appropriate did not inculcate them into their communication pattern. It has been suggested that the health care environment prevents the full integration and maximum utilization of communication skills that is therapeutic (Mathews, 1962; Mynatt, 1985). Further research in this area is warranted to deepen our understanding of these processes.

Baer and Lowery (1987) in their study examined how patient character and helping situations affected the predisposition of nursing students to caring for patients and reported that these students preferred to care for patients who were cheerful, communicating and accepted their illness and care provided. The finding of this study highlights the fact that when considering the nurse-patient interaction, the characteristics of patient communication pattern was an important variable to consider (Garvin and Kennedy 1990). The use of Peplau's psychodynamic nursing theory in investigating the nurse-patient interaction is understandable as it includes both the patient and the nurse actively, thereby addressing the points stated by Garvin and Kennedy.

Roter's interaction analysis system was used by Caris-Verhallen et al., (1998) to analyze the communication pattern of nurse-elderly patients in home care and long term care facilities and they reported that communication in relation to nursing care occurred more frequently in home care than in the long term care facilities where relationship related communication was more frequent. Self selection and performance bias were limitations to these studies as nurses selectively recruited patients that participated in the study and the presence of a video recorder could affect the pattern of communication used by the nurse. Although this study increases the theoretical research base of knowledge of types of nurses' communication pattern and when they are used, it does not improve the understanding of the nurse-patient relationship.

In a study of speech acts and style of ten (10) registered nurses with older clients in two different nursing homes, it was reported that majority of the nurses 
South American Journal of Nursing

Special Edition 2016

communication elicited verbal elaboration from the patients eliciting mono-syllabic yes or no answers and that nurses rarely gave up control of procedures in patient care (Gibb and O'Brien, 1990).

\section{Nurse-patient interaction}

This was the focus of various studies in the context of terminal illnesses, chronic illness, care of the elderly, labor and delivery and psychiatry (Aranda \& Street, 1999, Cleary and Edwards, 1999).

Altschul(1971), in an early study on nurse-patient interactions in the United Kingdom reported controversies about whether or not nurses should form relationships with patients as some opined that it was a "dangerous" both for the patients and nurses. In observing this, Altschul interviewed the nurses and patients about their experience in the interaction as to whether such relationship was considered therapeutic. Patients in these nurse-patient relationships believed in its therapeutic effect however, nurses expressed their doubt about the therapeutic value of the relationship with the patient. The fact that the relationship was not seemingly purposeful or goal oriented made the researcher conclude that the relationships are not therapeutic. Some interviewed nurses were said to have berated colleagues who fostered therapeutic relationships with their patients while they were also involved in varied levels of nurse-patient relationships.

According to Altschul (1971), patients and nurses alike reported an awareness of a nurse-patient relationship but the nurses seemed oblivious of the patients view. In quantifying the frequency and length of nurse-patient interactions it was found that nurses 'were not in frequently interacting with the patients' However, this finding however, did not exclude nurses from relationships with patients; in three of four examples (on one psychiatric unit), the researcher observed only one interaction of a short interval initiated by the patient). Therefore, the nurse-patient relationship was not dependent on prolonged periods of multiple interactions. These findings opposes the belief that time is important for the development of a nurse-patient relationship that is satisfactory, this is consistent with the report of Hagerty and Patusky (2003) who reported that extended time interval was not a necessary requirement for a relationship to be formed.

Altschul (1971) reported that some patients, spoke at length about certain nurses when asked what had helped them while in the hospital, mentioned specific names, each nurse was described vividly making it very obvious the depth of information patients had about nurses individually (Altschul, 1971). Common finding to Altschul (1971) and Shattell (2002) are that patients prefer genuine nurses, who are patient, not hurried, available and willing to talk to them which contrast the findings of shattel (2002) on the clinical environment.

Joan Halifax (2013) stated that nursing practice is grounded deeply in the experience of compassion- based relationships. A deficit of which might be relevant to the patients experience of care, affecting nurse-patient interaction. It is the capacity to feel concern for and attend to the experience of others, to sense what will serve others, and potentially be of service to them. Compassion is said to have two main valences: the affective feeling derivable from caring for a suffering one and the motivation to relieve them of the sufferings (Hoffman et al., 2011).

In 2002, in a study on the role of nurse-patient interaction on the wellbeing and recovery of patients in the critical care units, the following were identified as interactive characteristic behaviors of nurses and patients both negative and positive.

Nurses interactions that are positive:

Sharing: the nurse faces the patient and offers such items such as prescribed food, water, an audio cassette player, a radio, urinal or other materials used in the support of the patient's treatment. 
Praising: comments that involves approving, recognizing or commending the patient, such as "very well done", "you look much better today", and "you are really recovering fast". All comments should involve audible, clear and a sonorous voice, this may or may not involve physical contact.

Visual contact: The nurse maintains eye to eye contact with the patient for as long as he is at the patient's bedside regardless of whether the patient is looking at her/him unless when he is engaged in a procedure that would not allow for such.

Brief contact: The nurse maintains contact within the patient's personal space which should be no longer than an arm's length, for a period not less than five seconds.

Proximity: Same as above but involves contacts beyond five seconds

Smiling: looking the patient in the eye and lifting the corners of the lips.

Verbal request: making a request or suggestion verbally which must be audible? examples include "(patient's name), "could you please lift your arm", "please turn on your side so that I can raise your headrest", "you are going to feel a mild sting but it will hurt very little", "we will be giving you a sponge bath".

Modeling: Body movements or changes accompanied by the corresponding verbalization, replicated by the patient within ten seconds.

Laughing: Opening the mouth congruently or lifting the corners of ones lips while emitting a voiced laughter sound sometimes accompanied by a comment such as "that was funny"

Physical contact: the patient is hugged or patted by the nurse

\section{Characteristics negative interaction}

Ignoring the patient: When the patient makes a request or ask a question, the nurse fails to respond congruently in more than five seconds, or does not carry out the requested action without rationalizing his inaction, or simply nods without establishing visual contact.

Yelling: Loud comments of disapproval. Examples: "Hey, that was really bad!", "Don't get out of bed!", "Don't remove that bandage!

Disapproving: Verbalizations implying disagreement, disgust or criticism by the nurse.

\section{Patients positive interaction}

Maintaining attention: The patient keeps sustained eye contact while the nurse provides an explanation, information, instruction or appropriate comment.

Requests: Includes verbal, digital or manual indications (in case of verbal impossibility) expressing a need or request, followed by the corresponding nurse appropriate behavior. Examples: requesting a glass of water, pain medication, etc.

Praise: A verbalization or clearly distinguishable gesture expressing gratefulness or approval of an action by the nurse

Acceptance: After the nurse offers or performs a health related or comfort providing function, the patient says "yes", "mmhm", thanks the nurse, nods affirmatively with the head, eyes or hands expressing agreement acceptance or satisfaction

\section{Patients negative interaction}

Disagreement (negativity): Verbalizations expressing opposition to nurse's actions. Examples: "I don't want that medicine", "don't move me", "don't touch me", "I don't want to eat", "leave me alone".

Yelling: Same as above in the absence of a justifying situation such as acute pain, extreme discomfort or other urgent need. 
South American Journal of Nursing

Special Edition 2016

Ignoring: Same definition as above for nurses in absence of a justifying situation such as being asleep or unconscious.

\section{Patient perception of nurse-patient interaction}

Studies that explored patient perceptions of nurse-patient interactions sought to explore the perspectives of patients on the competence of nurses in terms of interpersonal interactions as well as the patients experience of care when labeled as non-compliant or difficult (Fosbinder, 1994 \& Breeze and Repper, 1998).

In 1994, Fosbinder reported from the study on patients perception of the nurseclient interaction in which patients were asked about their experiences and feelings while accessing nursing care, patients talked mostly about the interpersonal interactions rather than the other aspects of care with emphasis on communication, friendliness, humor, personal sharing, trust and going the extra mile. It was also acknowledged that the patients role in the nurse-patient interactions be studied in future. Peplau's psychodynamic nursing theory could aid our understanding of the nature of nurse- patient interaction in terms of reciprocity by helping us understand communication patterns.

Another study which explored patient's view of the nurse-patient interactions in terms of exclusion and confirmation among patients hospitalized (Drew, 1986). Exclusion meaning utter disregard for ones feelings especially by a significant other on whom one depends while confirmation is the acknowledgement of one's feeling especially by a significant other. Interviews were conducted to the participants individually in whom they were required to describe a negative and a positive experience with the nursing staff. Experiences of patients regarding exclusion in their interaction with nurses in the hospital settings were characterized by care givers responses which were cold emotionally avoided eye contact and hurried. Caregivers that are enthusiastic, energetic, made eye contact and physically relaxed as well as indulged the patients in personal sharing were characterized as confirmatory.

Drew's (1986) study also shows that caregiver communication and behavior impacts on patient. Patients negatively affected by experiences of exclusion reported feeling like energy was being sapped and confirmatory experiences was described as energy infusing thus the effect this interaction could be either confirmatory or exclusionary and helpful or harmful. These findings are consistent with those of Plaas (2002) and Shattell (2002) who reported that patients sometimes experienced the hospital environment as somewhat disconfirming and disconnecting. In a phenomenological study of the outpatient health care environment, Plaas (2002) reported that patients reported feelings of being treated like objects. Studies of both in-patient and out-patient environments have findings which are consistent with those of Drew (1986).

Based on previous studies on deviant behaviors (Lemert, 1972), social labelling of patients and moral evaluation is well outlined in the literature (Jeffrey \& Stockwell, 1984).

The labeling of patients affects patient care in the hospital environment. The label "non-compliant", 'difficult' and 'bad' has been associated with 'demanding, uncooperative, and ungrateful patients, these patients create a feeling of ineffectiveness in the caregivers (Finlay, 1997). Patients who are labeled as "difficult" are usually avoided by the nursing staff which results in nursing care that is poorly supportive (Carveth, 1995).

Breeze and Repper (1998) in a study that was ethnographic on the experiences of mental health patients using nine mental health nurses focus groups to study the perception of patients on their experience of care by examining the characteristics of patients they deemed to be difficult. The following characteristics were identified: does not respond to intervention, diagnosis of personality disorder, does not conform, 
multiple and complex needs, disruptive and aggressive, long-term mental health problem, demanding (of staff, time or resources), (Breeze \& Repper, 1998). Six patients who met the 'criteria' of the 'difficult' label were then interviewed. The researchers initially compiled a list of 17 patients, but the researcher encountered difficulty in interviewing them. Even the patients interviewed by the researchers were not easy to contact. For example, they had to visit one participant about four times just to explain the study and give consent. From their data analysis, Breeze and Repper (1998), findings included three main themes- nursing interventions, patient response and control. Patients reported feelings of little or no control over their treatment; they were being coerced into more appropriate behaviors in the opinion of the staff. The response of participants to this situation was anger and a struggle for control. The following were nursing interventions that were positive in natureaddressing the patient with respect, empathetic, holding normal and regular conversations with the client, a good nurse-patient relationship, enhancing patients control over their care, listening to and believing in the patient (Breeze \& Repper, 1998). The participants expressed a desire to be respected and valued as a person which is consistent with the report of Plaas (2002).

\section{Patient care-seeking communication}

Studies on the activities of patients in the nurse-patient interactions are very few. An implicit assumption among many others is that the care giver is empowered to effect changes and influence the care giving situation (Russell, 1994). The few studies that addressed patient activity in terms of communications were contextually in pain management and care seeking of the elderly (Pettegrew \& Turkat, 1986; McDonald et al., 2000, Russell 1994 \& 1996).

Two empirical studies performed at a clinic in a university medical centre reported that clinic patients were some mailed measurement tools - Patient Communicator Style Measure (PCSM), Illness Behavior Inventory (IBI), and measure of the utilization of medical treatment. The PCSM measured the construct communication style i.e. how people communicate- found to be valid and reliable. It consists of nine sub constructs- open communication style, dominant communication style, contentious communication style, friendly communication style, relaxed communication style, attentive communication style, animated communication style precise communication style, and dramatic communication style. The illness behavior Inventory measures the way people communicate in illness and has the following subconstructs- social illness behavior and work illness behavior (Pettegrew and Turkat 1986). They also reported in their second studying which they videotaped seven patient-provider interactions to differentiate the personal reports of the clients and an independent rater's assessment. There was no significant difference found between patient self report and the independent raters assessment of communication behavior. Although there were no significant differences in the two groups statistically, it was noted that the patients who reported an assertive communication style were found to be inappropriate, uncooperative and contentious by the independent raters. How do patient communication variables affect the nurse-patient interaction and health outcomes? How does the power differential impact the interaction? How could the use of psychodynamic nursing theory impact the nurse-patient relationship, both in research and practice? Further study is warranted and as Pettegrew and Turkat (1986) aptly conclude, 'patients may have a far greater impact on and responsibility to the health-care relationship than previous provider-patient research has revealed'.

Russell (1996) in another study on patient communication and care seeking behavior used semi-structured interviews and participant observation with older patients in a long-term care facility to examine the insight of the care-receivers' into 'successful care interactions'. It was found that elders used their previous experience 
to manage future interactions with caregivers; he also described a care seeking process which consist of care eliciting and engaging. This process emerged from experiences with formal and informal caregivers as was developmental and sequential in nature (Russel 1994 \& 1996). It will be appropriate to explore in depth the sequence of events that take place when patients seek care. Peplau's theory of Psychodynamic nursing would be an appropriate framework for use.

\section{Discussion}

Peplau's theory of psychodynamic nursing was reviewed to further our understanding of the interaction between nurses and patients. Threats to face may be greater in situations in which patients and nurses interact and vulnerability is threatened but when the nurse is attuned to self and the patient, this threat is removed, nurses frequently find themselves in a position to probe about intimate matters, in this situation, patients will be comfortable to discuss personal issues with them when the nurse engages personal sharing as a tool to probe. Patients in highly vulnerable crisis depend upon nurses for basic needs. Both of these situations are illustrations of common nurse-patient interactions where the potential for the patient's loss of face (autonomy, self-esteem) is high hence the need for high level of psycho-dynamism. A better understanding of the nurse-patient relationship using the psycho-dynamism theory may 'provide an alternative viewpoint for the social phenomena of interest to nursing within the construction of verbal conversation' socially. (Donald \& Watson, 1996, Spiers, 1998).

Studies on the nurse-patient interactions increased our knowledge on the pattern of communication nurses adopt in their interactions with patients, patients' perception of the relationship and their interactions with nurses. Nurses were found to be favorably empowered and exercised some level of control on patients. The communication skills of nursing students did not improve with training and work experience related to nursing. Nurses steered clear of patients labeled as 'bad' or 'difficult' which causes a decline in the quality of care afforded them. Nurse-patient relationships are formed after a few interactions irrespective of how relatively short the duration is. Patients attached some level of importance to these relationships much more than other aspects of the nursing care. Patients required that nurses to be genuine, available, not in a hurry and willing to communicate with them. Patients emphasized on their valued and self respect as individuals believing that social interaction was paramount but would not be treated as objects.

\section{Implications for clinical practice}

Findings from this review have many implications especially for clinical practice. The interaction between nurses and patients influences the patient's care experience therefore, it should be considered vigilantly. McDonald et al. (2000) in a study on patient pattern of communicating the need for analgesics post-operatively reported that some patients avoided or delayed communicating their needs as they do not want to be noted as always complaining. Do patients have patterned ways of communicating with nurses in an effort to manage their relationship? Do nurses pay enough attention to recognize the subtle ways in which patients air their needs?

Most of the literatures reviewed on the subject explored the communicative action of nurses thus ignoring the patient's contributions (May, 1990). Although a greater percentage concurred that the interaction is central to nursing practice, a few studies addressed patients as equal partners in the interaction. Morse et al. (1997) asserted that there has been a form of deliberate ignoring of the patient's behavior when nurses examine the nurse-patient relationship, a further research is therefore needed to examine the patient's contribution to this relationship. 
Majority of the studies reviewed that examined patient communication have used linguistic that is non-theoretical, communication that is based on content and orientation which leads to a limited understanding of the role the patient plays in nurse-patient interaction.

\section{Suggestions for further studies}

Further research questions remain: How do ill patients transmit information to nurses? How does the patient's style of communication affect nurse-patient interaction and the outcome of healthcare, quality of care and patient satisfaction? Will greater satisfaction be derived from nursing care when patients use a dominant or assertive style of communication? What methods are the best to access the 'difficult' patient in the clinical environment and for research purposes? The literature reviewed in this paper has presented the existing research on nurse-patient interactions. Much about the patient's contribution remains unknown. The use of Peplau's Psychodynamic theory could help us narrow this gap.

\section{References}

[1]. Altschul A. (1971) Relationships between patients and nurses in psychiatric wards. International Journal of Nursing Studies 8, 179-187.

[2]. Aranda S. \& Street A. (1999) Being authentic and being a chameleon: nurse-patient interaction revisited. Nursing Inquiry 6, 75-82.

[3]. Baer E. \& Lowery B. (1987) Patient and situational factors that affect nursing students' like or dislike of caring for patients. Nursing Research 36, 298- 302.

[4]. Breeze J.A. \& Repper J. (1998) Struggling for control: the care experiences of 'difficult' patients in mental health services. Journal of Advanced Nursing 28, 1301-1311.

[5]. Breeze J.A. \& Repper J. (1998) Struggling for control: the care experiences of 'difficult' patients in mental health services. Journal of Advanced Nursing 28, 1301-1311.

[6]. Caris-Verhallen W., Kerkstra A., van der Heijden P. \& Bensing J. (1998) Nurse-patient communication in home care and institutional care: an explorative study. International Journal of Nursing Studies 35, 95-108.

[7]. Caris-Verhallen W., Kerkstra A., van der Heijden P. \& Bensing J. (1998) Nurse-patient communication in home care and institutional care: an explorative study. International Journal of Nursing Studies 35, 95-108.

[8]. Carveth J.A. (1995) Perceived patient deviance and avoidance by nurses. Nursing Research 44, $173-178$.

[9]. Carveth J.A. (1995) Perceived patient deviance and avoidance by nurses. Nursing Research 44, $173-178$.

[10]. Cleary M. \& Edwards C. (1999) 'Something always comes up': nurse-patient interaction in an acute psychiatric setting. Journal of Psychiatric and Mental Health Nursing 6, 469-477.

[11]. Cleary M. \& Edwards C. (1999) 'Something always comes up': nurse-patient interaction in an acute psychiatric setting. Journal of Psychiatric and Mental Health Nursing 6, 469-477.

[12]. Cleary M., Edwards C. \& Meehan T. (1999) Factors influencing nurse-patient interaction in the acute psychiatric setting: an exploratory investigation. Australian and New Zealand Journal of Mental Health Nursing 8, 109-116.

[13]. Cleary M., Edwards C. \& Meehan T. (1999) Factors influencing nurse-patient interaction in the acute psychiatric setting: an exploratory investigation. Australian and New Zealand Journal of Mental Health Nursing 8, 109-116.

[14]. Donaldson, J. M., Watson, R., (1996). Loneliness in elderly people: an important area for nursing research. J Adv Nurs.

[15]. Drew N. (1986) Exclusion and confirmation: a phenomenology of patients' experiences with caregivers. Image: Journal of Nursing Scholarship 18, 39-43.

[16]. Finlay L. (1997) Good patients and bad patients: how occupational therapists view their patients/clients. British Journal of Occupational Therapy 60, 440-446. 


\section{South American Journal of Nursing Special Edition 2016}

[17]. Forchuk, C., et al. (2000). The developing nurse-client relationship: Nurse's perspectives. Journal of the American Psychiatric Nurses Association, 6(1), 3-10.

[18]. Fosbinder D. (1994) Patient perceptions of nursing care: an emerging theory of interpersonal competence. Journal of Advanced Nursing 20, 1085-1093.

[19]. Garvin B. \& Kennedy C. (1990) Interpersonal communication between nurses and patients. Annual Review of Nursing Research 8, 213-234.

[20]. Gibb H. \& O’Brien B. (1990) Jokes and reassurances are not enough: ways in which nurses relate through conversation with elderly clients. Journal of Advanced Nursing 15, 1389-1401.

[21]. Hagerty B.M. \& Patusky K.L. (2003) Reconceptualizing the nurse-patient relationship. Journal of Nursing Scholarship 35, 145-150.

[22]. Halifax, J. (2011) The precious necessity of compassion. Journal of Pain and Symptom Management. (41) 146-153

[23]. Harrison T., Pistolessi T. \& Stephen T. (1989) Assessing nurses' communication: a crosssectional study. Western Journal of Nursing Research 11, 75-91.

[24]. Harrison T., Pistolessi T. \& Stephen T. (1989) Assessing nurses' communication: a crosssectional study. Western Journal of Nursing Research 11, 75-91.

[25]. Haug M. \& Lavin B. (1981) Practitioner or patient - who's in charge? Journal of Health and Social Behavior 22, 212-229.

[26]. Hewiston A. (1995) Nurses' power in interactions with patients. Journal of Advanced Nursing (21) 75-82.

[27]. Hofmann, S.G., Grossman, P., \& Hinton, D.E. (2011) Loving-kindness and compassion meditation: Potential for psychological interventions. Clinical Psychology Review (31) 1126-1132.

[28]. Jackson S. \& Stevenson C. (2000) What do people need psychiatric and mental health nurses for? Journal of Advanced Nursing, 31, 378-388.

[29]. Jeffrey R. (1979) Normal rubbish: deviant patients in casualty departments. Sociology of Health and Illness 1, 98-107.

[30]. Johnson M. \& Webb C. (1995) The power struggle of social judgement: struggle and negotiation in the nursing process. Nurse Education Today 15, 83-89.

[31]. Lemert E.M. (1972) Human Deviance, Social Problems, and Social Control, 2nd edn. PrenticeHall, Englewood Cliffs, NJ.

[32]. Lorber J. (1975) Good patients and problem patients: conformity and deviance in a general hospital. Journal of Health and Social Behaviour 16, 213-225.

[33]. Martin G. (1998) Empowerment of dying patients: the strategies and barriers to patient autonomy. Journal of Advanced Nursing 28, 737-744.

[34]. Mathews B.P. (1962) Measurement of psychological aspects of the nurse-patient relationship. Nursing Research 11, 154-162.

[35]. May C. (1990) Research on nurse-patient relationships: problems with theory, problems with practice. Journal of Advanced Nursing 15, 307-315.

[36]. McDonald D.D., McNulty J., Erickson K. \& Weiskopf C. (2000) Communicating pain and pain management needs after surgery. Applied Nursing Research 13, 70-75.

[37]. Morse J.M., Havens G.A. \& Wilson S. (1997) The comforting interaction: developing a model of nurse-patient relationship. Scholarly Inquiry for Nursing Practice: An International Journal 11,321343.

[38]. Muff J. (1982) Socialization, Sexism, and Stereotyping: Women's Issues in Nursing. Mosby, St Louis, MO.

[39]. Mynatt S. (1985) Empathy in faculty and students in different types of nursing preparation program. Western Journal of Nursing Research 7, 333-348.

[40]. Pearson T. (1975) The sick role and the role of the physician reconsidered. Millbank Memorial Fund Quarterly/Health and Society 53, 257-278.

[41]. Peplau, H. E. (1999). Interpersonal relations in nursing: A con- ceptual frame of reference for psychodynamic nursing. New York: Springer.

[42]. Pettegrew L. \& Turkat I. (1986) How patients communicate about their illness. Human Communication Research 12, 376-394. 


\section{South American Journal of Nursing \\ Special Edition 2016}

[43]. Plaas K. (2002) Like a bunch of cattle: the patient's experience of the outpatient health care environment. In Listening to Patients: A Phenomenological Approach to Nursing Research and Practice (Thomas S. \& Pollio H. eds). Springer, New York, pp. 214-236.

[44]. Powers B. \& Knapp T. (1995) A Dictionary of Nursing Theory and Research, 2nd edn. Sage, Thousand Oaks, CA.

[45]. Roth J. (1972) Some contingencies of the moral evaluation and control of clientele. American Journal of Sociology 77, 839-856.

[46]. Russell C. (1994) Older adults care recipients' insight into their caregivers: 'beware the stonefaced elephant!'. Geriatric Nursing 15,308-312.

[47]. Russell C. (1996) Elder care recipients' care-seeking process. Western Journal of Nursing Research 18, 43-62

[48]. Savage J. (1997) Gestures of resistance: the nurse's body in contested space. Nursing Inquiry 4, 237-245.

[49]. Schwandt T. (1998) Constructivist, interpretivist, approaches to human inquiry. In The Landscape of Qualitative Research: Theories and Issues (Denzin N.K. \& Lincoln Y.S. eds). Sage, Thousand Oaks, CA, pp. 221-259.

[50]. Shattell M. (2002) Eventually it'll be over: the dialectic between confinement and freedom in the phenomenal world of the hospitalized patient. In Listening to Patients: A Phenomenological Approach to Nursing Research and Practice (Thomas S. \& Pollio H. eds). Springer, New York, pp. 214-236.

[51]. Shattell, M. (2004). Nurse-patient interaction: A review of the literature. Journal of Clinical

[52]. Spiers J.A. (1998) The use of face work and politeness theory. Qualitative Health Research 8, 2547.

[53]. Stockwell F. (1984) The Unpopular Patient. Croom Helm, Beckenham.

[54]. Taylor S., Pickens J. \& Geden E. (1989) Interactional styles of nurse practitioners and physicians regarding patient decision-making. Nursing Research 38, 50-55.

Websites:

[1]. http://nursing-theory.org/nursing- theorists/Hildegard-Peplau.php

[2]. http://currentnursing.com/nursing_theory/interpersonal_theory.html

[3]. http://slsu-coam.blogspot.com/2008/08/peplaus-psychodynamic-nursing 